\title{
Churajón y Chuquibamba
}

\section{Panorama de la Arqueología de la Costa Extremo Sur * \\ Por Federico Kauffmann Dorg}

Los datos aquí expuestos son extractos de los apuntes de clase de mi curso universitario de "Arqueología Peruana". Constituyen los principales elementos de que me sirvo en la exposición y somero examen del capítulo correspondiente al panorama arqueológico de la Costa Extremo Sur.

En la división por áreas culturales establecida, corresponde a "la Costa Extremo Sur la región costeña comprendida entre el valle de Chala y la zona de Tacna. El Dr. G. S. Vescelius, on un artículo reciente, sintetiza los rasgos naturales que corresponden al área que nos ocupa y enumera también las caracteristicas arqueológicas propias a ella ${ }^{2}$ Advierte que no hay en la costa peruana una franja de terra costanera fon compleja ni tan

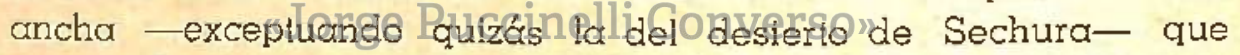
semeje la que se presenta en la región de la Cosla Extremo Sur. Encuentra hasta seis zonas distintas, en lo que respecta a la costa de Arequipa" - desde el litoral hasta las vertientes andinas"

1 Vescelius, 1960, p. 381-382.

La Costa Extremo Sur es dividida por Vescelius en "tres provincias naturales: 1) Ia provincia de Chala, 2), la de Tacna, y 3 ) la de Arequipa (que incluye la mayor parte del área)". Las seis zonas que se presentan en la provincia de Arequipa son, siempre según Vescelius: 1), el litoral, 2) la Cadena Costanera, 3) la Pampa desértica, 4) los Cerros preandinos, 5) las Cuencas preandinas (p. ej. Arequipa, Chuquibamba y Tarata) y 6) las Vertientes occidentales de los Andes.

* Vescelius señala las diferencias geoclimáticas entre la "provincia natural" de Arequipa y las otras dos provincias naturales: "La provincia de Tacna difiere de la provincia de Arequipa en que falta: 1) la Cadena costanera y 2) la Pampa desértica, ambas de las cuales terminan al Sur del río Sama. La provincia de Chala difiere en que: 1) falta el mar caliente y 2) los Andes llegan al mismo mar (es decir que no hay ni la Cadena costanera ni la Pampa desértica). Estrictamente hablando, la provincia de Chala es algo singular. 


\section{PROCESO \\ CULTURAL \\ EN LA \\ COSTA EXTREMO \\ SUR}

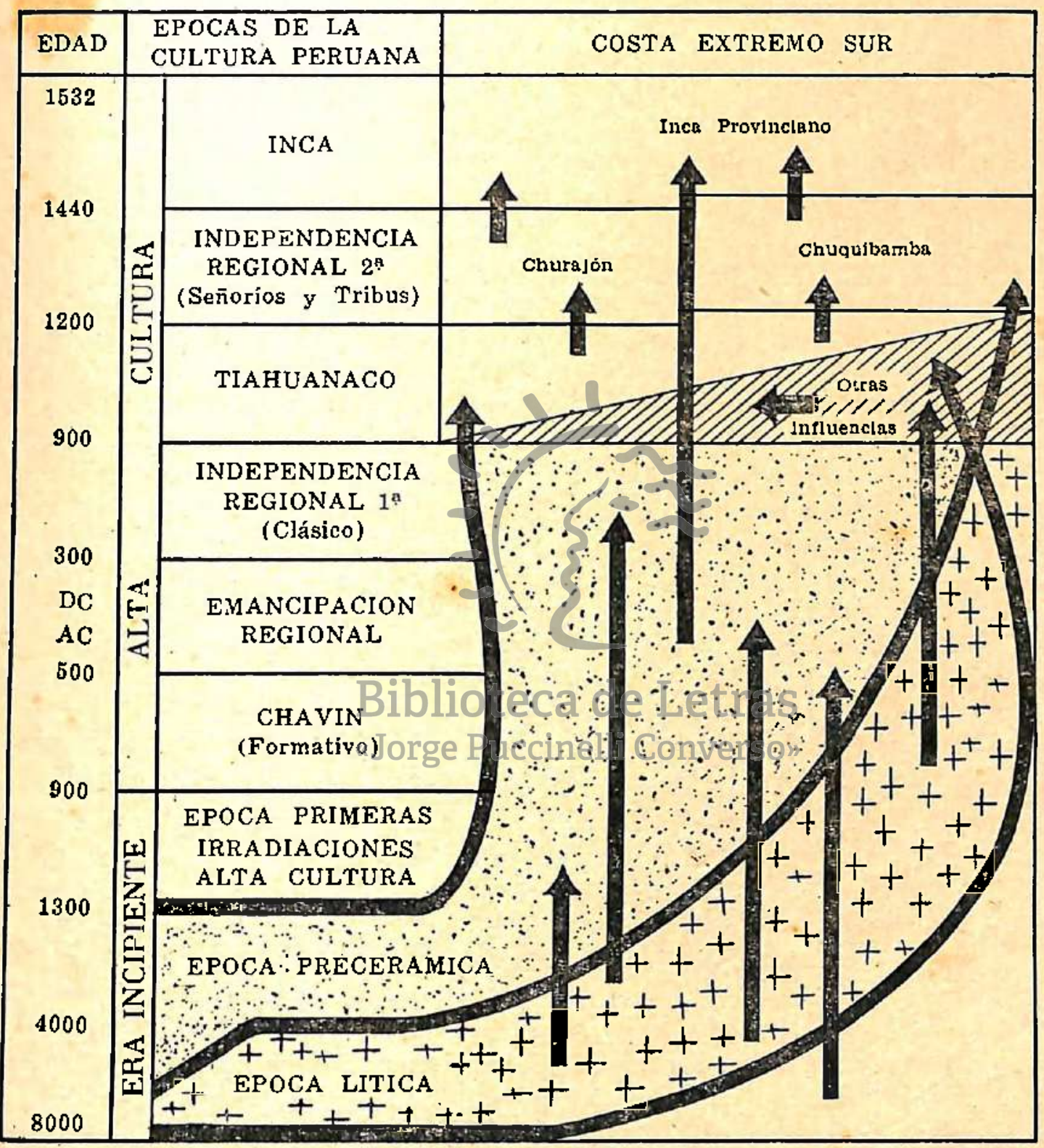

Sólo en la época Tiahuanaco el status cultural incipiente ea reemplazado, en la Costa Extremo Sur, por el de "alta cultura". (Las flechas indican las sobrevivencias). 
considerando como única en su género la extensa planicie o "Pampa Desértica", formada por rocas sedimentarias terciarias ".

Sólo a partir del período caracterizado por la expansión Tiahuanaco (Huari), la región de la Costa Extremo Sur se suma al ciclo de la alta cultura peruana, dejando atrás su carácter "precerámico". Las culturas Chavín, Paracas y Nasca, que se presentan en la Costa Sur (desde Acarí y Las Lomas hasta más al norte de Cañete), no influenciaron, pues, la región de la Costa Extremo Sur. Hay factores que hablan en pro de una relación con la llamada cultura Atacameña, advertidos desde tiempo atrás. Pero puede en este caso tratarse más bien de relaciones colaterales con lo Atacameño post-Tiahuanaco, motivadas por el fondo común tiahuanacoide. Ultimamente se viene remarcando que la Costa Extremo Sur debió estar más vinculada al Altiplano que a otra región, aunque siempre considerada en su etapa que arranca con la influencia Tiahuanaco (Huari), cultura que animará culturalmente la zona de la Costa Extremo Sur ${ }^{5}$.

El hecho mismo de que la Costa Extremo Sur careció de vinculaciones con el resto del área andina hasta sólo la época de Expansión Tiahuanaco ${ }^{8}$. ha motivado que los testimonios arqueológicos que presenta no tengan la singularidad del estilo Mochica, o el Nasca. En tiempos de estas culturas la Costa Extremo Sur se encontraba sumidar en und etapa/de cultura incipiente. Los estilos típicos de la región, desarrollados a partir de lo Tiahuanaco, son insípidos comparados con otros estilos peruanos. Esto en lo que toca a la cerámica, en la que se distinguen los estilos Chuquibamba y Churajón, y también en lo que se refiere a otras manifestaciones artísticas y artesanales.

Arqueológicamente, la región de la Costa Extremo Sur no ha sido favorecida por los estudiosos. Los cronistas ofrecen pormenores

4 Vescelius, 1960, p. 382

5 LUMBRERAS, 1962 , p. 63.

tipo chavinábamos encontrar en los estratos más profundos señas del tipo cnavinoide; pero luego de la revisión minuciosa de los fragmentos, nos hemos convencido que no hay restos tempranos..." Neira narra así su experiencia obtenida conjuntamente $\operatorname{con}$ G. Vescelius y H. Amat. 
sobre los pobladores de aquella zona, pero no con la minuciosidad como cuando tratan sobre los Chimú y otras tribus preincaicas anexadas al dominio de los Incas. Uhle visitó brevemente la zona de Arequipa, en $1905^{7}$. Más tarde, Kroeber, analizó los estilos de Churajón y Chuquibamba ${ }^{8}$. Los trabajos de Vescelius, ya citados, han promovido el interés por la Costa Extremo Sur. Sus depurados métodos se dejan ya sentir en la generación joven de arqueólogos regionales, especialmente entre los representantes muy recientes: Máximo Neira Avendaño y Hernán Amat O. El Director del Museo de Arqueología e Historia, de la Universidad de San Agustín de Arequipa, Profesor Eloy Linares M. promueve en la actualidad una intensa investigación arqueológica y gracias a él, Arequipa cuenta hoy con una revista especializada en la materia ${ }^{9}$. Pero sería injusto olvidar aquí a los pioneros de la arqueología arequipeña. Ellos son Mons. Bernedo Málaga ${ }^{10}$, descubridor de las ruinas de Churajón, y el Prof. José María Morante ${ }^{11}$.

En lo que toca a las referencias a grupos o naciones que poblaban la Costa Extremo Sur, las noticias antiguas son, como queda anotado, escasas y vagas en extremo. Sabemos que en el límite sur - de Arica en adelante- habitaba un grupo étnico conocido con el nombre de Chango, que tenía una economía de pesca y agricultura incipiente ${ }^{12}$. Hay también noticias vagas sobre la presencia de gente Uru, en la zona del extremo norte de Chile y, según se afirma aisladamente Håmbién èn elsur del Perú. Se suele relacionar a los Uru, con los Puquina; ambos grupos habrían hablado una misma lengua, no Quechua, y dominado, según Bernedo Málaga ${ }^{13}$, en un tiempo no sólo en la sierra central y sur, sino también la Costa desde el norte de Arequipa hasta el norte de Chile, formando el "Imperio Uru". Esta suposición se presenta, a todas luces, falta de pruebas. Lo que se puede sacar en limpio es sólo que en la Costa Extremo Sur meridional, sobrevivió hasta los primeros tiempos coloniales vestigios de pobladores primitivos de la zona.

7 ROWE, 1960, p. 229.

8 KROEBER, 1944, pp. 11-23.

D Se titula Kontisuyo (Boletín del Museo de Arqueología e Historia). En 1961, aparecó el No 1, y en 1963, el No 2 .

10 BERNEDO MALAGA; 1949; 1951.

11 MORANTE, 1939; 1959 etc.

12 BIRD, 1946 b, p. 595 y sigts. Véase también, LATCHAM (R. E.):

Los Changos de las costas de Chile (Santiago de Chile, 1910).

13 BERNEDO MALAGA, 1958, pp. 46-47. 


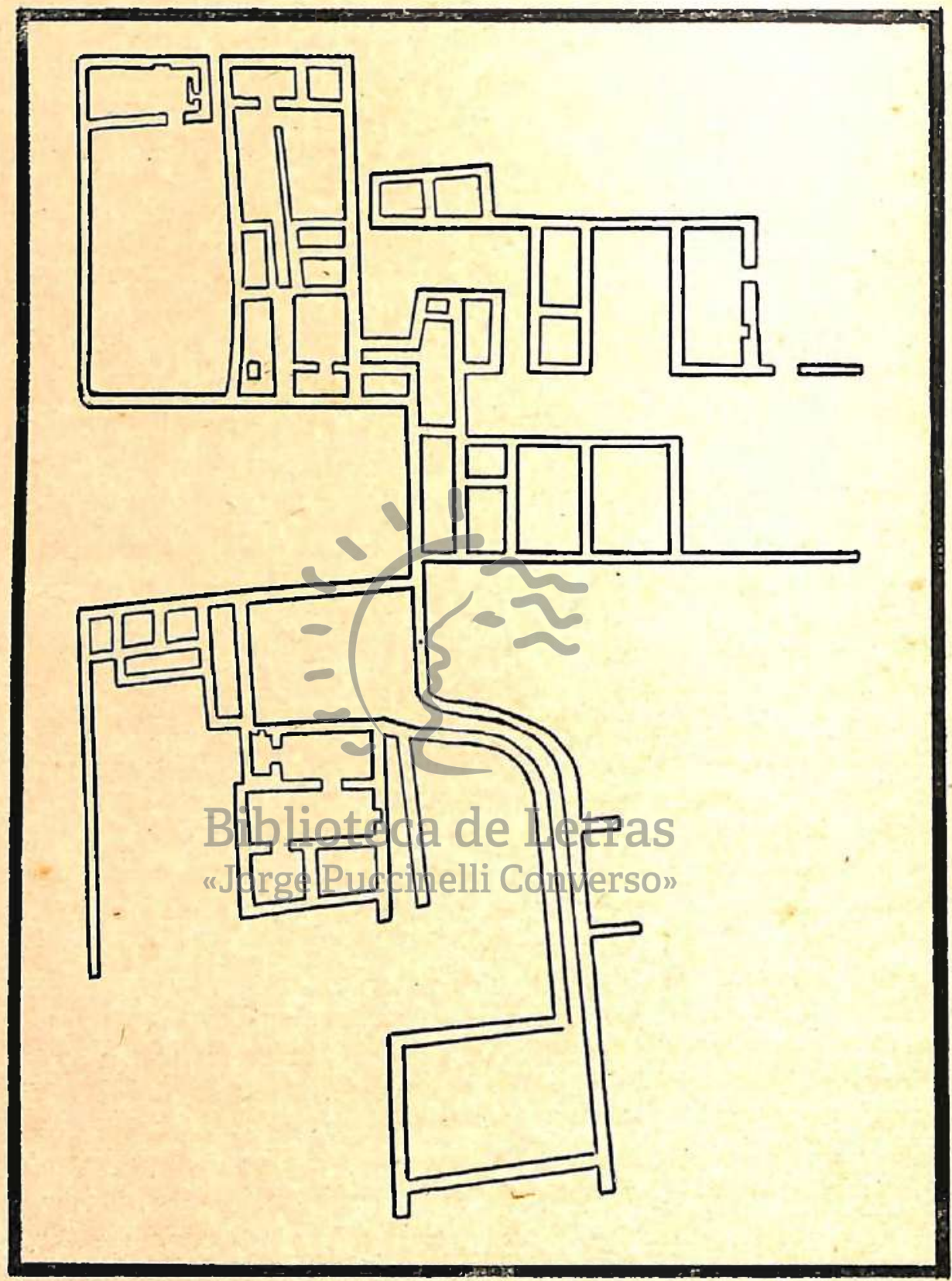

Croquis de lo parte principal de las ruinas de Churajón. Obsérvese los muros curvos y algunos otros trazos, similares a la arquitectura post-tiahuanuquense de regiones distantes o Arequipa, como, p. ej. lo de Chopijirca, Ancash, investigodo por el autor (Véose: Kauffmann Doig, "Las ruinas de Chopijirea". Lima, 1956), según Bernedo Mólaga, 1949. 


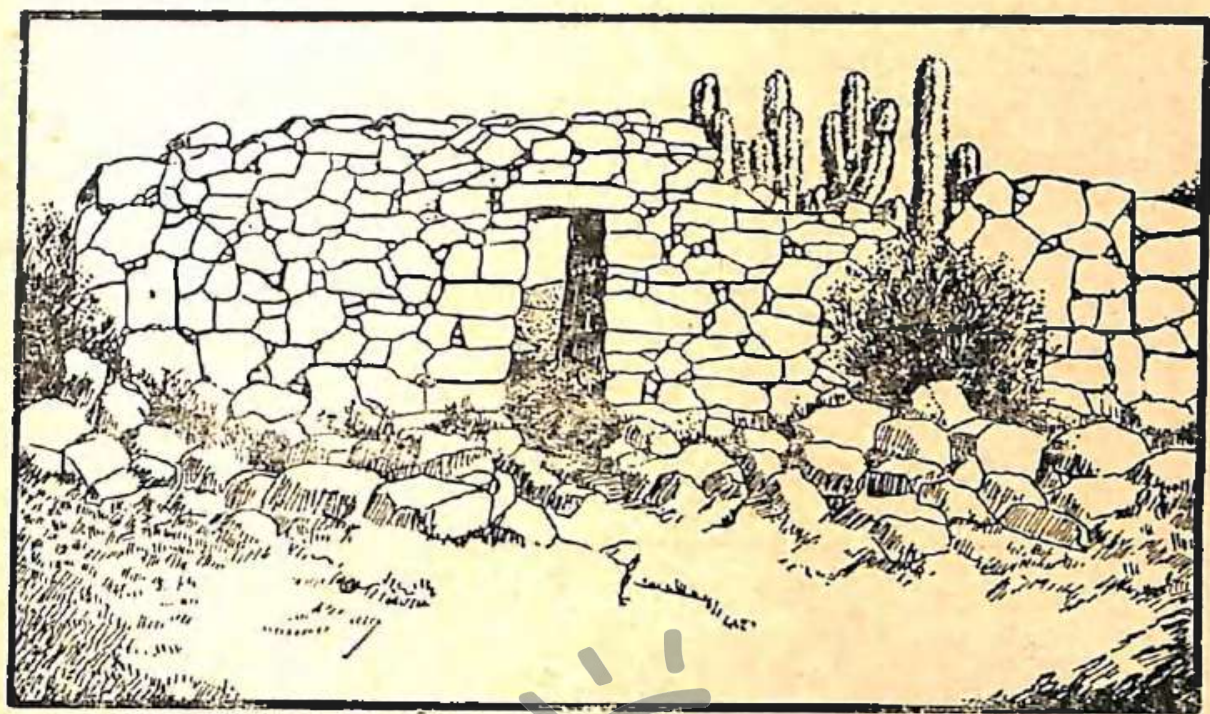

Construcciones y puerto en Churojón. (Bernedo Málaga, 1949 ).

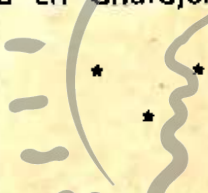

Con las manifestaciones culturales Tiahuanaco que se presentan hacia 800 ó 900 D. C. es probabie que llegara contingente colla o aymara; por lo menosedebiód difundirse enSla región esta lengua que, según «se dice, fue hablada por algunos núcleos hasta la llegada de los españoles. La Costa Extremo Sur recibió en su debido momento la influencia de la cultura Inca, conforme ha quedado comprobado arqueológicamente.

El problema arqueoiógico de la Costa Extremo Sur exige una ojeada sobre la cultura llamada Atacameña, y también sobre la arqueología de Arica. La zona de Arica es tabulada en la región de los Andes Meridionales. Se ha hecho notar que en Arica, además del Tiahuanaco Expansivo, se presenta la cerámica Negrasobre blanco, llamada también Arica $I^{14}$; de origen extra Tiahuanaco, tal vez derivada de la veta alfarera Atacameña de rasgos típicos cuya tradición se inicia antes de Tiahuanco. Este estilo evolucionó en Arica II, gracias a nuevas combinaciones e influencias, probablemente de la cerámica Collao; alfarería negra

14 BIRD, 1946, p. 589, etc. 
sobre rojo esta última que parte del Altiplano y se hace presente lanto en Arica como en Tacna ${ }^{15}$. Cuando Uhle revisó la arqueología de Tacna y Arica 10, llegó a la conclusión de que la cultura lítica habia sobrevivido en esa región hasta el advenimiento de Tiahuanaco y que el estilo Chincha había influenciado el Sur, hasta Ataca$m a$, y que a su vez el estilo Chincha y el Chincha-Atacameño, habían sido la base del estilo Inca ${ }^{17}$. Los resultados obtenidos por Bird, durante sus excavaciones en el Norte de Chile, muestran que cerámica alacameña autóctona se da desde tiempos anteriores a Tiahuanaco ${ }^{18}$, con lo que queda relegada la vieja tesis de Uhle ${ }^{19}$, seguida y detallada por Latcham ${ }^{20}$. En lo que toca a la influen-

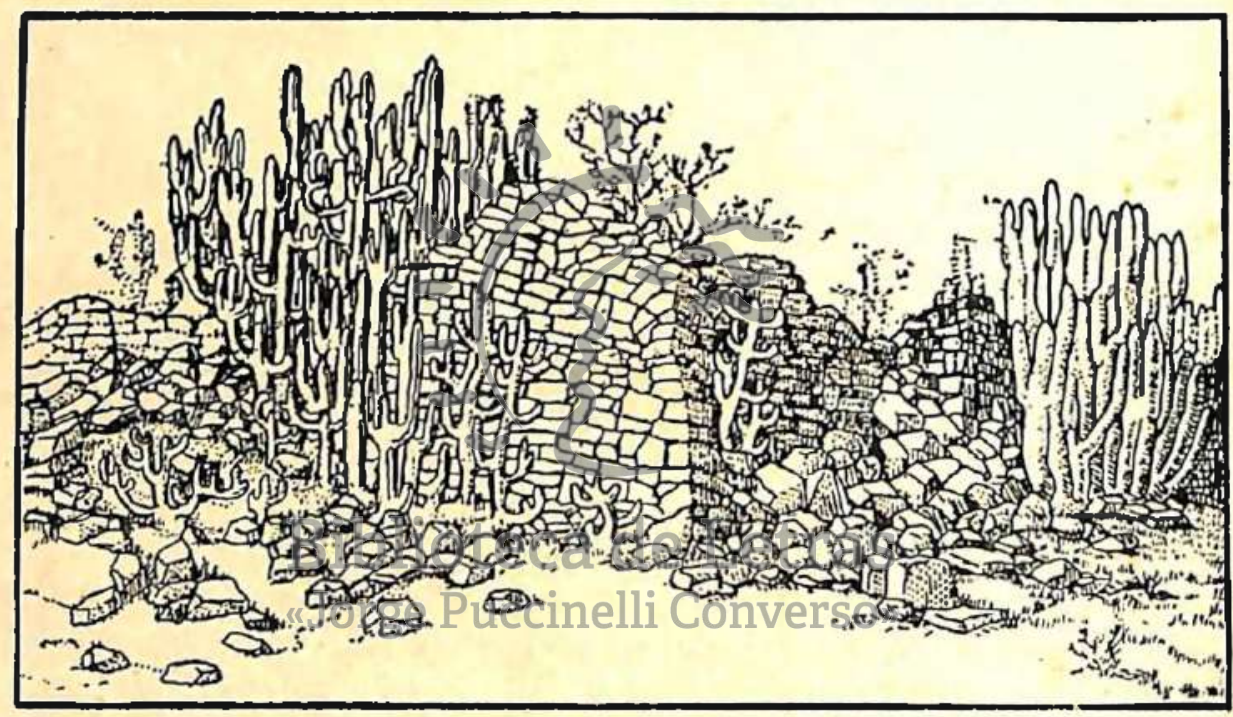

Un aspecto de las ruinos de Churajón (Bernedo Málaga, 1949).

cia del estilo Chincha en los confines meridionales de la Costa Extremo Sur, mejor dicho en la cultura Atacama, esta ha sido discutida por Kroeber. Refiere que la única base que se puede presentar en favor de la influencia Chincha sobre la región atacameña es la ocurrencia en ambas áreas de una vasija de base redonda $y$ amplia boca con dos asas laterales, e insiste en que estas ca-

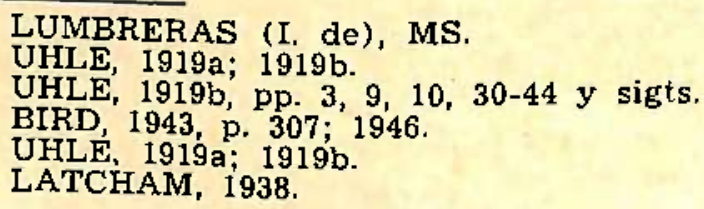



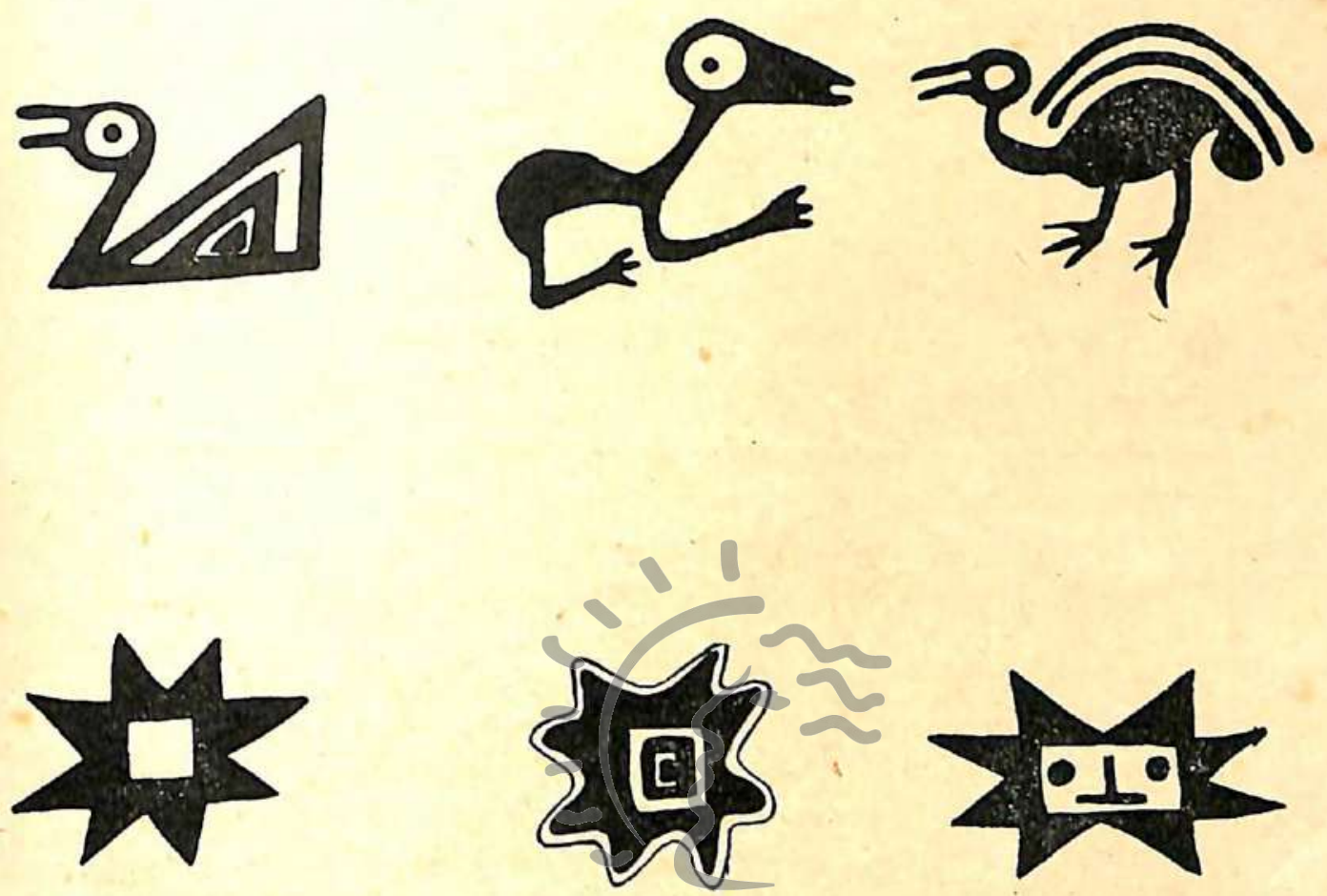

\section{Biblioteca de Letras "Jorge Puccinelli Converso"}
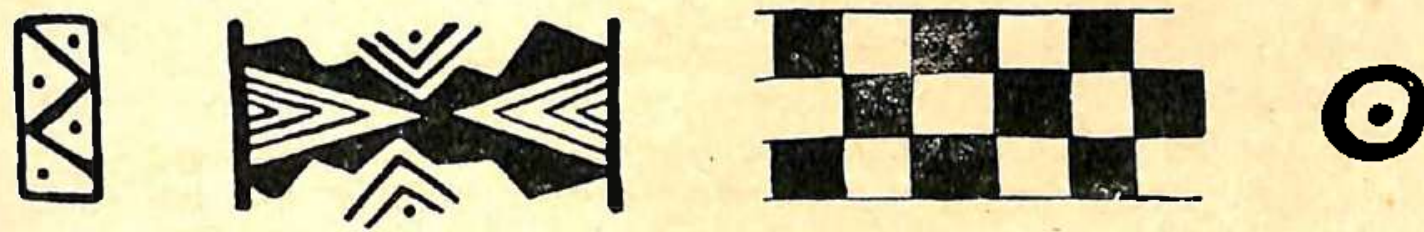

Motivos decorativos de la cerámica Chuquibamba. Hilero superior: dibujos figurativos; hilera central lo "estrella de ocho puntos; hilera inferior: diseños geométricos (Entresacodos de los dibujos presentodos por M. Neira: "Los Collagua", Arequipa, 1962, pp. 202 a y b) 
racterísticas no tienen mayor trascendencia en la cerámica de una y otra zona, y aún más, que no son siempre del todo semejantes en cada caso ${ }^{21}$. La posición de Bennett es de ordenación. Habla de una cultura básica de la región, la Atacameña, establecida en épocas tempranas, o por lo menos anterior a toda infiuencia Tiahuanaco. Posteriormente recibiría, de tiempo en tiempo, influencias, entre otras, de Tiahuanaco $\mathrm{y}$, especialmente, del estilo Churajón de Arequipa; concluye que, con todo, mantuvo el estilo original (Atacameño) su idiosincrasia, hasta la conquista española $=2$. El estilo Churajón y la base tiahuanacoide parecen ser, también, los fundamentos de la serie Chiribaya (Ilo), recolectada por $\mathrm{H}$. Ghersi en $1954^{23}$.

En lo que se refiere a la cerámica que más caracteriza la Costa Extremo Sur -la llamada Churajón- esta se encuentra por toda la provincia de Arequipa y al Sur, con más o menos variantes, hasta Moquegua y Locumba ${ }^{24}$. Ha sido llamada Pukina-Atacama por Tello25. Fue revisada por Kroeber ${ }^{20}$, y, nuevamente, por Rowe, utilizando el material recolectado por Uhle en 1905 para la Universidad de California ${ }^{27}$. El nombre de Churajón - cuya cerámica pretende hoy rebautizar E. Linares con el nombre de Yuli ${ }^{28}$ - deriva de unas ruinass ${ }^{20}$, cercanas a Chapi, ubicadas a unos $50 \mathrm{~km}$. de Arequipa. En ese sitio L. Bernedo Málaga realizó excavaciones hallando cantidad de cerámica, que entregó al Museo de la Universidad de-San Agustín ${ }^{30}$-Sus informes están inundados de suposiciones y, en su espíritu general, sus obras siguen, con candor religioso, algunas de las "doctrinas" de Posnansky. Con todo, es interesante resaltar su obra de pionero en la arqueología de la región de Arequipa. Las ruinas de Churajón son men-

21 KROEBER, 1944, p. 17. 2: 599-619. Washington, 1946), p. 602.

23 GHERSI, 1956.

24 Los restos arqueológicos de Chuquibamba, capital de la provincia de Condesuyos, parecen tener sus características propias. La provincia de Cailloma con la zona Collagua, en el interior, es territorio típicamente serrano.

2.5 TELLO, Origen..., pp. 108-110 (Lima, 1942).

23 KROEBER, 1944, pp. 11-16 y sigts. (Publica varias piezas en fotografía de la col. Escomel, adquirida por el Museo Nacional y dibujos de procedencia distinta.

27 ROWE, 1960.

28 LINARES, 1962 , p. 90.

29 También llamadas Sahuaca o Sawaka.

30 BERNEDO MALAGA, 1958, pp. 71-76. 
cionadas en documentos diversos -estudiados por Bernedo Málaga- con el nombre de "La Huaca" que, según la tradición trasmitida por el indio Juan Huaranca, fue centro donde dominaba el cacique de Churajón ${ }^{31}$. Cerámica semejante se encontró accidentalmente en 1941, en Tingo, en un cementerio que fue explorado por M. Suárez Polar y José M. Morante, en el sitio denominado Tres Cruces ${ }^{32}$. Esta cerámica es, en términos generales, tosca; de color rojo, negro, y blanco; de paredes gruesas y modelada en forma burda; usa diseños geométricos, frecuentemente de tipo zig zag irregular pintado en banda gruesa. M. Neira, después de un análisis tipológico de 300 cerámicos, presenta -luego de depurar su clasificación inicial ${ }^{33}$ - el siguiente esquema, con validez tipológica más no cronológica ${ }^{34}$ :

\section{Churajón Sencillo \\ II Churajón Engobado \\ III Churajón Bicromo \\ IV Churajón Policromo \\ V Tres Cruces Policromo \\ VI Churajón Modelado}

En lo que se refiere a la cerámica llamada Chuquibamba ${ }^{35}$, Kroeber advertía ya que era distinta a la de Churajón; no hay duda que pertenece a una misma época; es decir, se trata de una tradición especial, vecina y contemporánea a Churajón. Con todo es el estilo Churajón especiaimentelel que sobrevive y persiste aún en los primeros tiempos coloniales. El estilo Chuquibamba se encontró por vez primera en la provincia de Condesuyos (Dep. Arequipa), que es el límite sur - según Kroeber-, de las influencias de la región de más al norte, o sea de la Costa Sur ${ }^{36}$. La cerámica Chuquibamba presenta vasos abiertos, pintados de negro so-

\footnotetext{
31 BERNEDO MALAGA, 1958, p. 72.

32 NEIRA, i961, p. 63.

33 NEIRA, 1961 p. 64-71.

34 Esta clasificación no difiere en lo substancial de la de Linares (1962 p. 90).

35 KROEBER, 1944, p. 19-22; NEIRA, 1961, p. 197 y sigts.

30 KROEBER, 1944, p. 19-22. (Este autor indica cierta influencia Nasca en Chuquibamba, negada por Neira (1961, p. 197), y que también aquí se considera muy problemática. J. M. Morante (1946, 1949), señala más bien influencia Collagua, en la cerámica negro sobre rojo de Chuquibamba. "Collagua" está tomado aqui en el sentido que daba Tello a una cerámica Tiahuanaco, llamada también Pacheco (Costa Sur).
} 

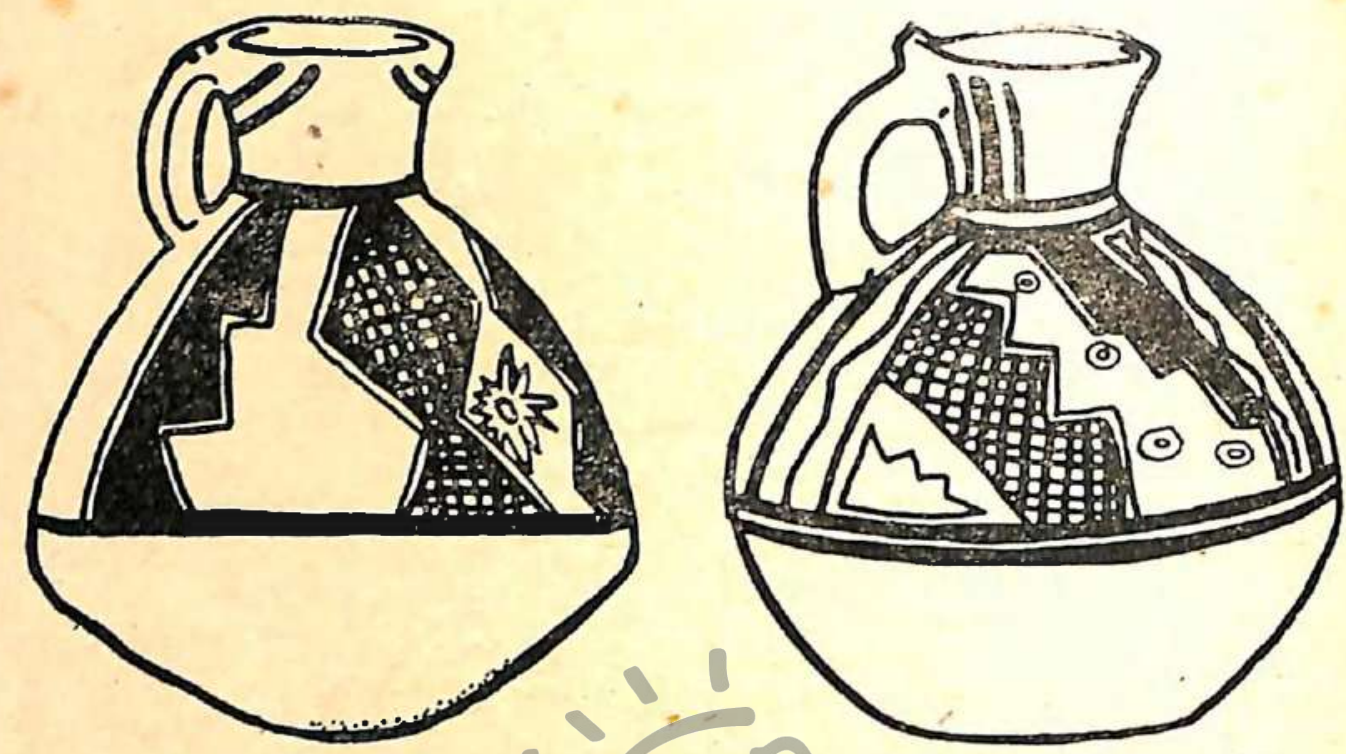

Dos cerámicos Churojón que conserva el Museo de lo Universidad de Arequipa.

(Bernedo Máloga, 1949).

bre fondo rojo oscuro, formas varias distintas a las de Churajón; diseños en líneas simples, a veces blancos; J. M. Morante ha llamado la atención sobre una característica de la decoración de Chuquibamba: la "estrella de ocho puntas". Esta se considera típica. Contra la opinjóñ de Derothy Menzel g Luis Lumbreras, quienes sostienen que es un motivo autóctono, surge la posición de Junius Bird ${ }^{38}$.

La arquitectura de la Costa Extremo Sur, además del centro impórtante de Churajón, cuenta con otros muchos exponentes. Con todo, se carece de lo monumental, y de las técnicas soberbias de labrar la piedra, como en Chavín, Tiahuanaco o en el período Inca. La obra de ubicación de ruinas arqueológicas efectuada en el Museo de la Universidad de San Agustín en los últimos años merece ser destacada, aunque se trate de un inventario provisional toda-

38 Carta de Junius Bird a Gary Vescelius (11-III-1960, transcrita parcialmente por Neira (1961, pp. 200-201), quien además comenta la opinión de Menzel y Lumbreras, citando información verbal. La tercera posición es que este moitvo pudo ocurrir en el Perú, como en otros lugares americanos y no americanos, en forma independiente. 
vía falio de método ${ }^{30}$. Es interesante subrayar que las construcciones en la Costa Extremo Sur no se levantan, como en el resto de la costa, de adobe, sino de piedra. Por otra parte es importante recordar que no se dan huacas levantadas con plataformas, tan características en la Costa Norte, Central y Sur; en cambio sí, como lo anota Vescelius en su informe sintético, hay profusión de
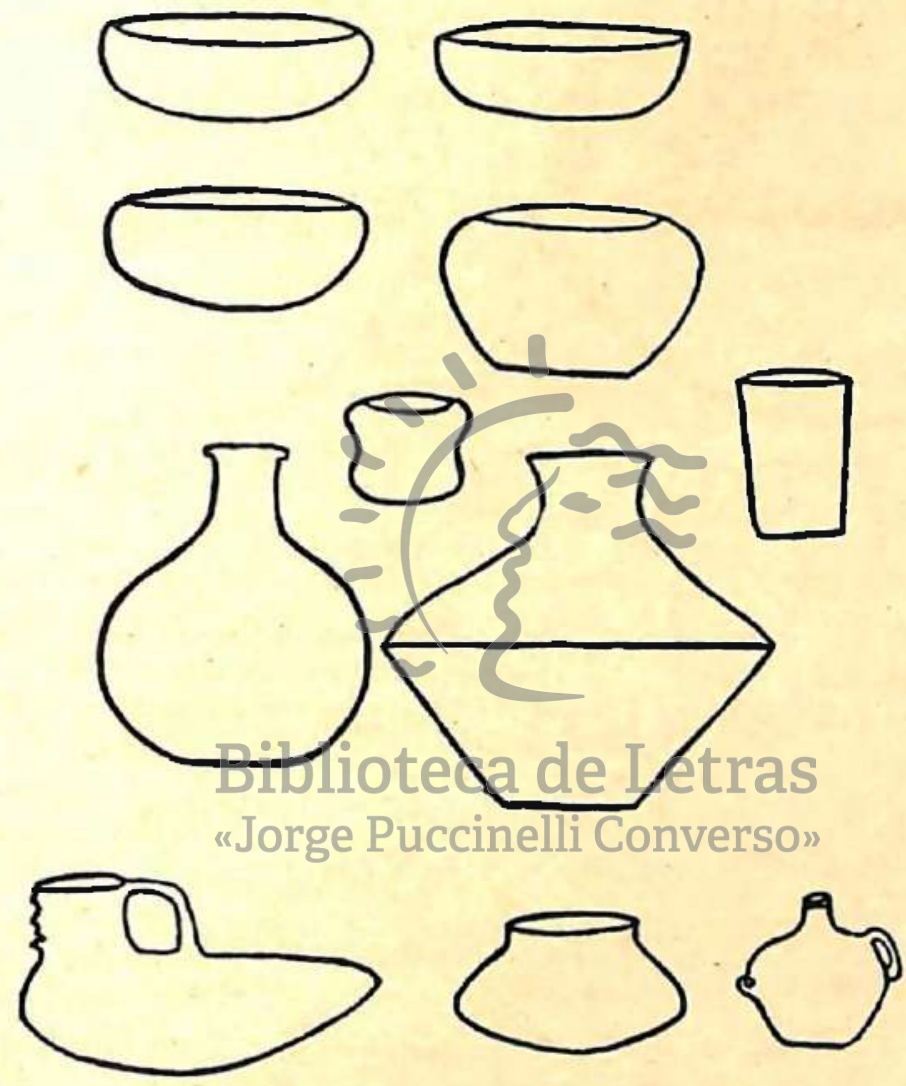

Cerámica Chuquibamba (M. Neira: "Los Collagua".

Arequipo, 1961, p. 201 o)

Chullpas, construcciones que en la región costanera restante prácticamente no se dan ${ }^{40}$. Estas características en el aspecto arquitectónico contribuyen a aislar la Costa Extremo Sur del resto de la Costa, y a vincularla - según la tendencia actual- a la región de la Sierra.

39 LINARES, 1961.

40 VESCELIUS, 1960, p. 382. 


\section{BIBLIOGRAFIA}

(De la Costa Extremo Sur)*

\section{BASADRE (Modesto)}

1884a "Una momia muy antigua". Riquezas peruanas (Colección de artículos descriptivos escritos para "La Tribuna") pp. 26-90. Lima.

1884b "El hombre primitivo". Riquezas peruanas. (Colección de artículos descriptivos escritos para "La Tribuna") ,pp. 1-14. Lima.

BERNEDO MALAGA (Leonidas)

1949 La cultura Puquina o prehistoria de Arequipa. Lima,.. (Se-

1951 "Gunda edición: Lima, 1958). Arequipa.

BIRD (Junius)

1943 Excavations in Northern Chile. Anth. Papers Am. Mus. Nat. Hist., v. 38, No 4. New York.

1946a "The cultural sequence of the North Chilean Coast". Handbook South Am. Indians, 2: 587-597. Washington.

$1946 \mathrm{~b}$ "The historic inhabitants of the North Chilean Coast". Handbook South Am. Ind:ans, 2: 595-597. Washington.

CARPIO (Alfredo)

1942 "Datos sobre la arqueología de los valles de Acarí y Yauca". XXXVII Cong. Int. Am., 1: 485-529. Lima.

\section{DAUELSBERG (Percy)}

1960 "Contribución al estudio de la arqueología del valle de Azapa". Antiguo Perú Espacio y Tiempo, pp. 273-296 + 6 pp.

1963 "Algunos problemas sobre la cerámica de Arica" (Conse:vatorio Arqueológicoi del ExtremorSur, Arequipa, 1960). Kontisuyo, 2: 4-23. Arequipa.

ESPEJO NUÑEZ (Julio)

1941 "Las viejas necrópolis halladas recientemente en Tingo, Arequipa (Novedades arqueológicas)". Chasqui, 1 3: 79-80. Lima.

GHERSI (Humberto)

1956 "Informe sobre las excavaciones en Chiribaya". Rev. Mus. Nac., 25: 89-119. Lima.

KIMMICH (José)

1921 "Arqueología arequipeña; viaje arqueológico a Pocsi. El Deber, 6-IX. Arequipa.

KROEBER (Alfred L.)

1944 "The southern coast" (Peruvian Archeology in 1942., pp. 11-23) New York.

LATCHAM (Richard)

1938 Arqueologia de la región atacameña. Santiago.

1942 "Correlaciones arqueológicas entre Perú y Chile". XXVII Cong. Int. Am., 1: 267-275. Lima.

* Incluye algunos estudios sobre la arqueología de Arica. No se mencionan en esta bibliografía obras generales, como "Origen..." de J. C. Tello, salvo en casos especiales. 
LINARES MALAGA (Eloy)

1960 "Notas sobre los petroglifos de Toro Muerto". Antiguo Pe-

1961 rú. Espacio y Tiempo, pp. 297-299. Lima.

1901 Clasificación alfabética de lugares y sitios tipo arqueológi-

cos en el Departamento de Arequipa. Ed. mim. Arequipa.

de los Fuéguidos. Ed. mim. Arequipa.

eológico en una régión

LUMBRERAS (Isabel F. de)

s. f. "Arqueología de Tacna, valles de Locumba, Sama y Caplina". (Cit. por L. G. Lumbreras: "Espacio y cultura en los Andes", Rev. Mus. Nac., 29. Lima,1950).

LUMBRERAS (Luis G.)

1962 "Sur y Norte en la cultura andina". Kontisuyo, 1: 59-66. Arequipa.

MALAGA (Toribio)

1933 "A propósito de las ruinas de Churajón". El Dcber, 28-X. Arequipa

MORANTE (José María)

1938 "Los estudios históricos y arqueológicos en el Departamento

1939 de Arequipa": El Deber, 15-VIII Arequipa.

1939 Arqueología del Departamento de Arequipa; Condesuyes y Camaná precolombinos (Tesis doctoral Univ. N. San Agustín, Arequipa).

1941a "Informe de las excavaciones arqueológicas en Tres Cruces". El Deber, 2-VI. Arequipa.

1941b "La necrópolis de Tres Cruces". El Deber, 23-VII. Arequi-

1946 "Arqueología arequipeña", Revista. Univ. N. S. Agustín. 24:

1949 "Arqueología de Arequipa". Rev. Univ. N. S. Agustín. 29:

67-76. Arequipa.

1.959 "La ascendencia pre-histórica de los pescadores del Litoral de Arequipa. Los Changos". Ir Cong. Nac. de Hist. del Perú. 1: 304-309. Lima.

MOSTNY (Greta)

1944 "Excavaciōnes en Arica". Bol. Mus. Nac Hist. Nat., 22: 135145. Santiago (Chile).

NEIRA AVEDAÑ̃ (Máximo)

1958 Ensayo de clasificación tipológica del estilo Churajón (Tesis Bach. Univ. N. San Aglistín) Ed. mim. Arequipa.

1961 Los Collaguas (Tesis Doctoral Univ. N. San Agustín AreROWE (John) quipa). Ed. mim. Arequipa.

1960 "Una colección arqueológica de Arequipa en el Museo de Antropología de la Universidad de California". Etmología y Arq. 1: 228-236. Lima.

SUAREZ POLAR (Manuel G.)

1941 "La necrópolis de Tres Cruces". Dl Deber, 27-III. Arequipa. UHLE (Max)

1919a "Fundamentos étnicos de la regíón de Tacna y Arica". Bol.

Soc. Ecuatoriana Est. Whist. Am., 2: 1-37. Quito.

1919b "La arqueología de Tacna y Arica". Bol. Scc. Ecuatoriana Est. Hist. Am., 3: 1-48. Quito.

VESCELIUS (Gary S.)

1960 "Rasgos naturales y culturales de la costa extremo sur". Antiguo Perú; Espacio y Tiempo, pp. 381-383. Lima. 


$$
-266-
$$

SUAREZ POLAR (M. G.)

1934 "Carta del Dr. M. G. Suárez Polar" (Recientes exploraciones arqueológicas en el Perú). Rev. Mus. Nac., 3: 176-178. Lima.

VALCARCEL (Luis E.)

1934a "Informe preliminar sobre las ruinas de Churajón" (Recientes descubrimientos arqueológicos en el Perú). Rev. Mus. Nac., 3: 175-176. Lima.

1934b "Respuesta del Dr. Luis E. Valcárcel" (Recientes descubri. Lima.

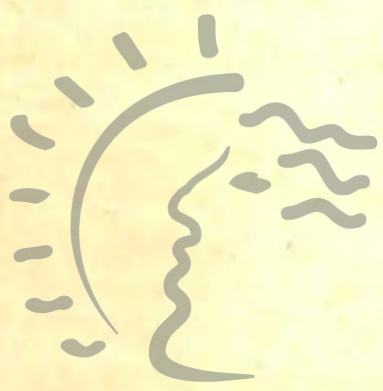

